\title{
Teachers' Perceptions of Aspects That Influence the Exclusion in Physical Education Class
}

\author{
Bruno Inocêncio Vicente ${ }^{1}$, Rachel Belmont ${ }^{1,2}$, Carlos Alberto Figueiredo da Silva ${ }^{{ }^{*}}$ \\ ${ }^{1}$ Graduate Program in Physical Activity Sciences, Salgado de Oliveira University, Niterói, Brazil \\ ${ }^{2}$ Graduate Program in Biosciences and Health Teaching, Oswaldo Cruz Foundation, Rio de Janeiro, Brazil \\ Email: bruno.inocencio@yahoo.com.br,rachelsbelmont@gmail.com, *ca.figueiredo@yahoo.com.br
}

How to cite this paper: Vicente, B. I., Belmont, R., \& da Silva, C. A. F. (2019). Teachers' Perceptions of Aspects That Influence the Exclusion in Physical Education Class. Advances in Physical Education, 9, 176-187.

https://doi.org/10.4236/ape.2019.93012

Received: May 6, 2019

Accepted: July 14, 2019

Published: July 17, 2019

Copyright $\odot 2019$ by author(s) and Scientific Research Publishing Inc. This work is licensed under the Creative Commons Attribution International License (CC BY 4.0).

http://creativecommons.org/licenses/by/4.0/

\begin{abstract}
The aim of this study was to understand how physical education teachers perceive the manifestations of exclusion in physical education classes. The study is characterized as a descriptive research with a qualitative approach. Semi-structured interviews were conducted with teachers from a public school in Rio de Janeiro city. The results pointed out the occurrence of several exclusion processes with greater emphasis on those involving gender issues and ethnic-racial relations. Pieces of evidence showed that the discussion about such topics should happen more effectively and present in university curricula, especially those focused on teacher education.
\end{abstract}

\section{Keywords}

Physical Education, Race, Gender, Exclusion

\section{Introduction}

Because groups previously disregarded and in socially vulnerable contexts began to demand greater economic, political, and cultural participation, some power relations, constructed historically and socially reproduced, were being destabilized. In this way, an ideological discourse is formed to justify the domination of some groups over others, and thus, shaping and naturalizing power relations and exclusion processes (Abramovay, 2002; Baquero, 2003; Silva \& Devide, 2008).

Exclusion processes occur in the most diverse institutions and with the most diverse social groups. Groups that deviate from a defined social standard are viewed in an unequal way and thus enjoy rights and access to services different- 
ly. The hegemonic class determines what the standard is, how subjects should behave and what they should consume to be part of the upper social strata, enjoying all privileges of the class (Bourdieu \& Passeron, 1992).

For the dominant class, the lower social strata represent the non-erudite cultures, classified as popular and their ethnicities, seen as inferior. In this way, more consolidated identities are built with fewer possibilities of emancipation. The social representations of each society built by the construction and internalization of its codes, symbols, and rituals, occurring through its agents in constant interaction (Alves-Mazzotti, 2008; Coulon, 1995; Madeira, 1991; Silva \& Votre, 2012). In this dynamic, the processes of exclusion by society, many everyday practices are tactical (Certeau, 2008). In this way, forgotten and silenced groups, even in the most adverse conditions, seek in the fissures of the obstacles imposed on them, an egalitarian form of representation. The difference happens as one of the multiple identities and possibilities that circulate in the social web.

Within this complex context, where the diverse cultures meet, there is the school, a social institution whose space should be democratic and multicultural, in order to allow the discussion of social problems. However, about the distribution of opportunities between genders, the school constructs, maintains and produces inequalities (Louro, 2014). In the ethnic-racial perspective, the content of school subjects is chosen to privilege a particular ethnicity/race to the detriment of others (Coelho \& Coelho, 2013; Crelier \& Silva, 2018; Pinto, 1999). Through the curriculum, the school politically builds the path which students must pass during their schooling process. The curriculum is one of the privileged places where knowledge, power, and social identities are mutually implicated (Silva, 1996).

The set of curricular components that compose the school curriculum aims to form critical citizens and mainly social intervenors (Brasil, 1996). As part of this more extensive process, physical education should transmit to students the culture of movement through the collection of bodily movements built throughout history (Kunz, 2004). For the subject to achieve this goal, it is essential to have a balance between the conceptual, attitudinal and procedural dimensions of the contents, allowing students to understand and experience the culture of the movement through several pedagogical practices. However, these objectives are not always in schools, either due to the lack of physical and material structure, as well as inadequate teacher training or work options. Therefore, it is limited that the opportunity of different motor experiences, and the specialization of few movements are valued, and may result in the exclusion of those considered unfits (Monteiro, 2013).

At this juncture, individualities, as well as different identities, are not appreciated, leading to the silencing of some groups. This process of exclusion may be overcome depending on the conceptions of physical education teachers and the relationships between identities, race, and gender that can be established in school physical education classes. The social world constructs the body through 
a permanent work of formation and imprints on it a program of perception, appreciation and action (Bourdieu, 2005), being full of actions that bring, in a naturalized way, in its structural bases, discriminatory marks which generate exclusion (Silva \& Devide, 2008).

To break with the crystallized and naturalized ways of conceiving bodies is essential to understand that the "cultural seals" they receive are mutable, transitory, and plural. It is necessary to think of the body as something constructed and in constant interaction with the cultural context in which it is inserted, as something produced in culture by culture (Goellner, 2008).

In the Brazilian socio-cultural scenario, although some growth of discussions about gender identity and ethnic-racial issues in recent years by different social groups the exclusion is still an underlying reality. The school as a social institution should offer learning environments that foster equality and promote reflection and discussion of these issues among students, education professionals, and the community. Understanding the workings of exclusion processes can help oppressed and excluded groups to face discrimination more effectively.

Thus, considering that physical education provides an essential contribution to education for citizenship and autonomy, the aim of this study is to understand how physical education teachers perceive the manifestations of exclusion that occur during their classes at school.

The study presents reflections that can help improve the actors involved in the educational process in order to minimize teaching proposals that foment exclusion processes and encourage those that comply with the principle of inclusion, valuing and respecting differences.

\section{Method}

This descriptive study with a qualitative approach was developed at the Integrated Center of Public Education in Rio de Janeiro city. This school was founded in 1994 and has classes from 1st to the 3rd year of high school in the three shifts, with 2300 students and 142 workers, and its structure is considered one of the best and most extensive in the neighborhood. This school is located in a poor community and represents most of the public schools under municipal government management.

The school investigated has 9 physical education teachers; 6 teachers ( 4 men and 2 women) agreed to participate voluntarily in the research. Of the remaining three, one said they did not have time for the interview, and two did not accept it, claiming to be the subject of much controversy, and therefore preferred not to talk about the theme. Teachers' experience in teaching physical education varied from 9 to 33 years, and in this school from 1 to 5 years.

Semi-structured interviews (Bauer \& Gaskell, 2015) conducted with the teachers were composed of 12 open-ended questions: 1) How were race and gender issues addressed during your undergraduate education? 2) Have you ever read any physical education literature that has addressed these topics? If so, how 
were the issues addressed? If not, why do you believe that the literature does not address these issues? 3) Have you ever heard about gender identity? In both positive and negative cases, explain what you understand about it. 4) So, for you, identity would be ... 5) So, for you, genre would be ... 6) Have you ever heard about the term race? In both positive and negative cases, explain what you understand by race. 7) Do you think there is any relationship between gender and physical education? If so, what are the approximations? If not, why do you think there are no approximations? 8) Do you think there is any relationship between race and physical education? If so, what are the approximations? If not, why do you think there are no approximations? 9) Do you perceive any racial or gender discrimination among students during your classes? If yes, what actions are taken? 10) Is it important that these topics are addressed in the school physical education classes? Why? 11) Give me an example of what you use in your classes to address such topics. 12) In your opinion, how do students represent the identities of race and gender in class?

The records obtained were analyzed following a semantic approach in the interviewees' speeches (Bardin, 2011). The interviews were transcribed in full and imported into the NVivo10 qualitative analysis software, having been analyzed based on the principles of the thematic analysis. The content analysis allows identifying, analyzing and describing patterns (themes) within a given report (Bardin, 2011). In this technique, the following steps were: 1) Pre-analysis, when the initial ideas were operationalized and systematized, from a "floating reading" of the material collected in the interviews, registering the first impressions. 2) Exploration of the material, when the organization occurred, phrases or fragments were identifying the "sense units" or meaningful conceptual units of teachers responses. 3) Treatment of results and interpretation, when inferences interpretations were made, based on the research objective. The emerging themes were then reviewed for their relevance to the purpose of this study and interpreted using the theoretical framework.

We classified the data into five main themes, which resulted from the progressive grouping of the elements. The titles of the thematic categories were defined during the accomplishment of the Pre-analysis and Exploration phases of the material.

The research was approved by the Institutional Ethical Committee. Teachers were volunteers and identified by random codes: T1, T2, T3, T4, T5, and T6.

\section{Results and Discussion}

The exclusion theme is on the agenda of most social institutions These discussions are the result of the search for equality and representativeness of groups seen as marginal (Louro, 2014). Because school is one of the main places (formal and systematized) of socialization and schooling through which the human being passes, being inequality and hierarchy part of their daily life, discussions like these could not be outside their walls. However, school education is one of the 
mechanisms of reproduction of the maintenance of established order, serving to legitimize inequality (Devide et al., 2011). Through the analysis of the data, it was possible to identify indications that highlighted emerging issues in the reports, namely: exclusion by gender, university education, racism, and intervention strategies.

\subsection{Exclusion by Gender}

About gender and physical education, the reports indicated the occurrence of a process of gender exclusion during classes. It was manifested in the unequal occupation of spaces and in the way that teachers use methodology to teach content. For example, teachers said: "That thing you get to the court, there only the boys are going to play soccer? And there the girls are excluded?! It is something that I also board in my classes in which I do not talk like this: the first time for girls and the second time for boys, I never do that" (T3). "I believe that in physical education classes this relationship is more evident. As we work with body language, society tends to understand that sports are for men and a few activities for women" (T5). "I have tremendous difficulty in developing with boys any activity other than football. With the girls, I have difficulty doing anything, because they do not want to do anything. I think this is already a gender problem, that story that boy only plays soccer and that girl does not do physical activity" (T6).

Even with the division of times or spaces, the boys tend to invade the spaces of the girls and little by little they take care of every block; leaving the girls the acceptation to that fact, as if the boys were by right and of natural form, owners of all the space (Altmann, 2015). T6 explained: "When I propose, for example, a game of burnt, the boys soon say that they will not play, because it is a woman's thing. When they accept to participate, do not let the girls play, claiming that they are weak and that they only stand still. At this point, they take up the whole class space, and the girls tend to accept it. Some of them even react a little, but in the end, how few, one or two, end giving up".

On the naturalization of the masculine imposition on the feminine in various aspects of social life, thinking of male domination, it anchors to modes of thought which are themselves the product of domination (Bourdieu, 2005). In the T4 report, there is an example of this: "It is well evidenced when you go to the practical part of physical education classes. Usually, the boys already take the ball and say: 'it is soccer', and the girls are already sitting. This is very clear when we start a class".

Another point present in the discourse is the type of activity taught in class. T1 stated that: "When I am going to give a dance activity, there is a bit of prejudice still about the boy who dances". T3 argued that the way content is approached and passed on to students may be favoring exclusion. "Many boys did not play soccer and talked like this: but, teacher, I like to play burnt. So, I started to adapt because of this question. Moreover, I was teaching even to myself, got 
it? I never said that again: ah soccer for boys and burned for girls" (T3).

The division between the sexes seemed to be "in the order of things", normal, natural, inevitable, functioning as systems of schemes of perception, thought and action (Bourdieu \& Passeron, 1992). This naturalization and acceptance of what is male and female in physical education classes can promote learning environments that lead to the exclusion by gender. However, according to T1 other forms of exclusion are also perceived in the school context. "Boys sometimes think girls cannot play futsal or do not have to play soccer. Discrimination in various ways, we perceive discrimination on account of gender, race, or an option, or students are more skillful, less skilled, or because they are chubbier or skinnier" (T1).

Aspects related to gender, strength, ability, and age form a tangle of exclusions. The intense and permanent social process of cultural production induces the kinds of "right" conducts that human beings must have to be accepted socially. The shape of bodies, the way of dressing, carrying, feeding, talking, and even the kind of physical activities chosen may indicate the social groups to which individuals belong. Thus, those who do not fit into the established profile are candidates to be socially excluded. In the T1 perception, the inequality of opportunity between boys and girls is related to the cultural context. "We have some cultural issues. For example, boys sometimes think girls cannot play futsal or do not have to play football. So, we have to work on this issue a little bit in their minds. Why cannot boys dance? These are cultural issues even from our own culture; we know that the girl is raised playing doll, the boy is raised a little looser, are issues of the culture that I believe is already changing that. We are entering a generation that this issue, this culture that the girl has to play doll and the boy that has to play ball is already changing a little, but still, have remnants of it in school" (T1).

Until the modernity, women could not even play any sport in the early Olympics of the modern era. The stereotypes attributed to the sporting modalities, associated with the masculine and the feminine, are socially constructed, and the degree of female participation in the sport depends on the cultural aspects of each society (Devide et al., 2011). One of Brazil's cases is soccer. Despite being the most popular sport in the country, the woman who plays soccer is discriminated against and suffers from prejudice (Daolio, 2006; Knijnik \& Vasconcellos, 2003; Souza \& Knijnik, 2007).

When we think about this aspect and its relationship with physical education classes, we can perceive that the distinction between boys and girls in the activities is a constant and generates generalized occupation of the spaces. A research (Altmann, 1998) observed for six months classes and recess of 4 classes of 5 grade in a public school of Belo Horizonte, Brazil, concluding that girls increased their area of action when the boys did not present themselves in the same space. Not very different from the Brazilian reality, another research (Thorne, 1993) investigated the theme in American schools and found that boys 
occupied 10 times more space in playgrounds and everyday activities, besides invading and interrupting games feminine often. Also, work with children playing on the street in the northeast of Brazil, in the state of Sergipe, corroborates this idea, because of the 32 children observed, $69 \%$ were boys and only $31 \%$ girls (Santos \& Dias, 2010).

\subsection{Intervention Strategies}

When asked if the gender theme should be addressed in the physical education class, it was possible to identify through the speech of T6, a reflection on the co-educative classes and the recognition that many of pedagogical strategies assumed during the classes can minimize the participation of the girls, imposing on them a secondary role. "I asked them to search, within the sports universe, games in which men and women practiced together. After the research, I asked them to introduce the sport to the group and to practice it. It gave a minimized in the prejudice because even without the mixture between boys and girls, the games would not occur and as they, the boys, wanted to play, they accepted" (T6).

Teachers are those who contribute the most to the concretization and reproduction of situations that are based on biological factors to determine the tastes of each sex. It is also necessary that teachers check their educational practices, combating stereotypes that may be inserted in class, making the discipline a transforming agent. Otherwise, inequality about corporal practices will continue to be reproduced, leading some groups, especially girls, to exclusion from physical education classes (Monteiro, 2013).

In the teachers' perception, the intervention strategies can contribute to minimizing prejudices that occur in the school environment and beyond, as T3 and T5 mentioned, when asked about the importance of addressing such themes in physical education classes. "Indeed, because this is how we go, as a professional, we are forming a generation without discrimination, without prejudice. Because this is important and so, especially in physical education classes, we see it coming out much more quickly than in the classroom. There, they sit quietly in physical education we perceive precisely, especially when about gender, it is much more outlined" (T3). "Absolutely. But not only in physical education, but in other disciplines as well. The teachers do not expose many of these contents, or when they are, they are part of the hidden curriculum, that is, they are not explicit in their planning" (T5).

\subsection{Undergraduate Education}

Notorious and positive is that all teachers interviewed said they used conversations, research, practical activities, among other methodologies, to intervene in the context of exclusion that has been occurring in classes. When asked about their undergraduate courses, no teacher affirmed having discussed themes such as gender and race/ethnicity in undergraduate subjects. Their teacher training 
education focused on motor skill performance. Until then, there was no concern about the teacher training courses with the reality found in the school physical education classes. T3 said that: "I do not recall that any professor addressed this issue at university time. Because I studied there in 1996 and in that time, the theme was not a very explored. So, it was not something so specific at the time, it was more technical training".

In the $\mathrm{T} 1$ perception, the absence of the subject in undergraduate and continuing education courses is because it is "a very controversial topic". "So it is, maybe it is people flee a little about it, about this, you know? Alternatively, because it is a much more current theme. I already graduated; it's over ten years old, right? It is a theme that is more present today; at that time did not discuss much it" (T1). Besides, for T5, universities assume conservative positions that make it difficult to discuss the theme. "I believe that both in my university years, as much as today, there is still significant resistance to these issues. There is a traditional bench within the university itself that blocks such matters. This aspect only reproduces what our society thinks about it. However, I see today a rupture of certain groups (blacks, women, transsexuals). There is greater widespread interest, a more progressive and less essentialist view on this" (T5).

However, the fact that they did not have contact with such discussions at undergraduate level does not place them in the position of ignoring the processes that lead to exclusion within physical education classes and creating their intervention strategies to prevent them. According to the responses, the contact with the themes occurred after undergraduate courses, through bibliographies of the educational area or in graduate courses. In many cases, the gender discussion is linked to the teachers' interest in the subject.

\subsection{Race/Ethnicity and Their Relationships}

In the question about the relationship between race/ethnicity and physical education, the teachers' answers related to situations or episodes that occurred outside school, usually in the sports world. T1 explained: "We have a few problems right now, of racism in the sport, especially in football, we see there in the news some cases of players who have suffered racism, right? So sometimes I talk to my students about this issue of racism in sports. Even last year I asked them to do an essay at the end of the year, talking about racism in the sport. What they thought about the subject and most of students highlighted that episode, which threw a banana peel in the field, of Daniel Alves, and that was very striking to them. So, I used to bring this subject to class sometimes, but not directly to address a question related to physical education, but to bias in general, you see? Tolerance, that's it".

Schools have difficulties in dealing with ethnic-racial issues, and there are no questions about the existence of this problem (Cavalleiro, 2000). Corroborating this statement, some teachers interviewed reported that they did not perceive racial/ethnic exclusion as strong as gender exclusion within the classroom. T3, for 
example, stated that: "Regarding race, no! It is very difficult today to see these racism manifestations in classes, at least in my work context. It is widespread for this mixture. Moreover, we live in Brazil".

T2 mentioned that the difference between whites and blacks is only physiological and should not be considered in classrooms within the school context, but rather in the training of athletes. He said: "At the time of college, our professor of physiology said that black people generally had a higher percentage of white fibers than white people. Moreover, you will see that there are more blacks with speed and explosion in comparison with whites. You see that in swimming, hardly see people black, why they have a higher bone density. He says that there was an absolute difference, but, every day as a physical education teacher I do not see any difference, understand? That is what I think is more for the question of athlete training, but in school physical education this does not influence anything".

In the perceptions of teachers interviewed, ethnic-racial prejudice occurs in high income and is outside the school environment. T2 believed that "in Brazil, it is difficult to speak of the race due to miscegenation". This speech exposes how much the ethnic-racial question is structural in Brazilian society to the point that issues of such importance and factors of social exclusion are considered as difficult to discuss. The school space is exclusive and reproduces of racism through several discriminatory mechanisms (Botelho, 2000).

\section{Conclusion}

Exclusion is a phenomenon that has occurred for decades in the school physical education classes. The culture of Brazilian society and the conformed posture of some teachers implies classes of physical education school where the separation of boys and girls persists. In this context, the classes create a hierarchy between the genders.

In the teachers' responses, it was possible to identify that exclusion processes are present in physical education classes of the investigated school. Issues related to gender and ethnic-racial were highlighted. The process of discrimination of girls is persistent and exposes the biological aspects as a marker determinant of exclusion. With this, the masculine group tends to have a higher occupation of the spaces and more significant time of the classes. For the girls, there remains the role of coadjuvants and an entirely different expectation about the classes.

Teachers did not sufficiently problematize issues related to ethnicity/race exclusion. In several responses, this issue does not appear to exist in the school setting. However, some reports pointed to the lack of discussion in undergraduate education and the consequent difficulty in addressing this issue in the daily classroom.

Although the teachers construct intervention strategies, the study identifies that these are still quite punctual and related to specific activities, this is not enough to minimize the exclusion processes that occur in class. It is not enough 
for the teacher to take an interest in the theme or to develop in his classes activities that seek greater equality. The search for more egalitarian relations must be the target of all citizens, institutions, and among them, the school. We need a renewed look at the new demands of the various groups that constitute the social whole. The ethnocentric view must be overcome, in the direction of a society where equity is the main principle and reference for any social construction.

It is urgent that the discussion of such themes occurs more effectively and presents in university curricula both in teacher training education and continuing education. Teachers should use pedagogical practices that foster inclusion, as well as to build solid arguments for discussions in school when situations that involve exclusion processes arise. It can help students to adopt new positions in situations that disrespect humanistic ideals and social justice.

Although the school studied has the same socioeconomic characteristics of most public schools in Rio de Janeiro, this study is limited by a small sample of teachers investigated. Due to the importance of the theme, new studies should go beyond the teachers' perceptions and propose planning, development, and evaluation of pedagogical practices to raise awareness and minimize exclusion in schools.

\section{Conflicts of Interest}

The authors declare no conflicts of interest regarding the publication of this paper.

\section{References}

Abramovay, M. (2002). Youth, Violenceand Social Vulnerability in Latin America: Challenges for Public Policies. Brasília: UNESCO.

https://unesdoc.unesco.org/ark:/48223/pf0000127138

Altmann, H. (1998). Rompendo fronteiras de gênero: Marias (e) homens na Educação Física. Master Thesis, Minas Gerais: Federal University of Minas Gerais. http://www.bibliotecadigital.ufmg.br/dspace/bitstream/handle/1843/FAEC-85ZJEJ/100 0000292.pdf? sequence $=1$

Altmann, H. (2015). School Physical Education: Gender Relations at Stake. São Paulo: Cortez.

Alves-Mazzotti, A. J. (2008). Social Representations: Theoretical Aspects and Applications to Education. Revista Múltiplas Leituras, 1, 18-43. https://doi.org/10.15603/1982-8993/ml.v1n1p18-43 https://www.metodista.br/revistas/revistas-ims/index.php/ML/article/download/1169/1 $\underline{181}$

Baquero, M. (2003). Building Another Society: The Social Capital in the Structuring of a Participatory Political Culture in Brazil. Revista de Sociologia e Política, 21, 83-108. https://doi.org/10.1590/S0104-44782003000200007

Bardin, L. (2011). Content Analysis. São Paulo: Edições 70.

Bauer, M. W., \& Gaskell, G. (2015). Qualitative Research with Text, Image and Sound: A Practical Manual. Petrópolis: Vozes.

Botelho, D. M. (2000). Educators in Confronting Racist Practices in Schoolspaces. Master 
Thesis, São Paulo: Universityof São Paulo.

Bourdieu, P. (2005). Masculine Domination. Rio de Janeiro: Bertrand Brasil.

Bourdieu, P., \& Passeron, J. C. (1992). Reproduction. Rio de Janeiro: Francisco Alves.

Brasil (1996). Ministério da Educação e Cultura. LDB Lei no 9394/96, de 20 de dezembro de 1996. Estabelece as diretrizes e bases da Educação Nacional. Brasília: MEC. http://www.planalto.gov.br/ccivil 03/leis/19394.htm

Cavalleiro, E. (2000). From the Silence of the Home to School Silence: Racism, Prejudice and Discrimination in Early Childhood Education. São Paulo: Contexto.

Certeau, M. (2008). The Invention of the Everyday: 1. Artsof Making. Petrópolis: Vozes.

Coelho, W. N., \& Coelho, M. C. (2013). Ethnic-Racial Content in Brazilian Education: Current Practices. Educação em Revista, 47, 67-84. https://doi.org/10.1590/S0104-40602013000100006

Coulon, A. (1995). Ethnomethodology. Petrópolis: Vozes. https://doi.org/10.4135/9781412984126

Crelier, C. M., \& Silva, C. A. F. (2018). Africanness and African-Brasilianness in School Physical Education. Movimento, 24, 1307-1320. https://doi.org/10.22456/1982-8918.81656 https://seer.ufrgs.br/Movimento/article/viewFile/81656/51908

Daolio, J. (2006). Culture, Physical Education and Soccer. Campinas: Unicamp.

Devide, F. P. et al. (2011). Genderstudies in Brazilian Physical Education. Motriz, 17, 93-103. https://doi.org/10.5016/1980-6574.2011v17n1p93

Goellner, S. V. (2008). The Cultural Production of the Body. In Body, Gender and Sexuality: A Contemporary Debate in Education (pp. 28-400). Petrópolis: Vozes.

Knijnik, J. D., \& Vasconcellos, E. G. (2003). Without Hindrance: The Open Heart of Women Who Wear Boots in Brazil. In With the Head on the Tip of the Boot-Essays on the Psychology of the Sport (pp. 2-18). São Paulo: Annablume/Ceppe.

Kunz, E. (2004). Didactic-Pedagogical Transformation of Sport. Ijuí: UNIJUÍ.

Louro, G. L. (2014). Gender, Sexuality and Education: A Post-Structuralist Perspective. Petrópolis: Vozes.

Madeira, M. C. (1991). Social Representations: Assumptions and Implications. Revista Brasileira de Estudos Pedagógicos, 72, 129-144.

Monteiro, M. V. P. (2013). Physical School Education and Gender Meanings: A Surveyat a State School in the City of Nova Iguaçu, Rio de Janeiro. Master Thesis, Rio de Janeiro: Federal University of Rio de Janeiro.

http://www.nutes.ufrj.br/mestrado/arquivos/Dis.MarcosViniciusPereiraMonteiro.pdf

Pinto, R. P. (1999). Ethnic-Racial Differences and Teacher Training. Cadernos de Pesquisa, 108, 199-231. https://doi.org/10.1590/S0100-15741999000300009

Santos, A. K., \& Dias, A. M. (2010). Play Behaviors among Children in Northeastern Brazil: Categorization of Play. Psicologia: Teoria e Pesquisa, 26, 585-594. https://doi.org/10.1590/S0102-37722010000400002

Silva, C. A. F., \& Devide, F. P. (2008). Discriminatory Language and Ethnomethods of Exclusion in School Physical Education Classes. Revista Brasileira de Ciências do Esporte, 30, 181-197. http://www.redalyc.org/articulo.oa?id=401338537013

Silva, C. A. F., \& Votre, S. J. (2012). Ethnomethodologies. Rio de Janeiro: HP Comunicação.

Silva, T. T. (1996). Identity Documents: An Introduction to Curriculum Theories. Belo Horizonte: Autêntica. 
Souza, J. S. S., \& Knijnik, J. D. (2007). The Invisible Woman: Gender and Sport in One of the Largest Daily Newspapers in Brazil. Revista Brasileira de Educação Especial, 21, $35-48$.

Thorne, B. (1993). Gender Play: Girls and Boys in School. New Brunswick, NJ: Rutgers University Press. 